\title{
The capsaicin receptor TRPV1 is the first line defense protecting from acute non damaging heat: a translational approach
}

\author{
Daniela C. Rosenberger ${ }^{1} \mathbb{B}$, Uta Binzen ${ }^{1,2}$, Rolf-Detlef Treede ${ }^{1}\left(\mathbb{D}\right.$ and Wolfgang Greffrath ${ }^{{ }^{*}}$ (D)
}

\begin{abstract}
Background: Pain is the vital sense preventing tissue damage by harmful noxious stimuli. The capsaicin receptor TRPV1 is activated by noxious temperatures, however, acute heat pain is only marginally affected in mice after TRPV1 knockout but completely eliminated in mice lacking TRPV1 positive fibers. Exploring contribution of candidate signal transduction mechanisms to heat pain in humans needs translational models.

Methods: We used focused, non-damaging, short near-infrared laser heat stimuli (wavelength 1470/1475 nm) to study the involvement of TRPV1-expressing nerve fibers in the encoding of heat pain intensity. Human psychophysics (both sexes) were compared to calcium transients in native rat DRG neurons and heterologously expressing HEK293 cells.

Results: Heating of dermal and epidermal nerve fibers in humans with laser stimuli of $\geq 2.5 \mathrm{~mJ}$ ( $\geq 25 \mathrm{~ms}, 100 \mathrm{~mW}$ ) induced pain that increased linearly as a function of stimulus intensity in double logarithmic space across two orders of magnitude and was completely abolished by desensitization using topical capsaicin. In DRG neurons and TRPV1expressing HEK cells, heat sensitivity was restricted to capsaicin sensitive cells. Strength duration curves (2-10 ms range) and thresholds (DRGs $0.56 \mathrm{~mJ}$, HEK cells $0.52 \mathrm{~mJ}$ ) were nearly identical. Tachyphylaxis upon repetitive stimulation occurred in HEK cells (54\%), DRGs (59\%), and humans (25\%).

Conclusion: TRPV1-expressing nociceptors encode transient non-damaging heat pain in humans, thermal gating of TRPV1 is similar in HEK cells and DRG neurons, and TRPV1 tachyphylaxis is an important modulator of heat pain sensitivity. These findings suggest that TRPV1 expressed in dermal and epidermal populations of nociceptors serves as first line defense against heat injury.
\end{abstract}

Keywords: Near infrared laser, Heat pain, Nociception, Desensitization, Primary sensory neurons

\section{Introduction}

Sensation of pain is maybe the most important sense quoad vitam since it protects against injury and tissue damage by harmful stimuli. Molecular sensors detecting thermal or mechanical tissue damaging stimuli,

\footnotetext{
*Correspondence: wolfgang.greffrath@medma.uni-heidelberg.de ${ }^{1}$ Department of Neurophysiology, Mannheim Center for Translational Neuroscience (MCTN), Heidelberg University, Ludolf-Krehl-Straße 13-17, 68167 Mannheim, Germany

Full list of author information is available at the end of the article
}

however, still remain elusive; particularly those detecting threat and not actual damage-the first line of defense. Translation of findings from one system level (in vitro) to another (in vivo) and finally to humans is one of the great challenges in medical science in general [15], as direct translatability of methods and tools, applicable at more than one system level, is often difficult [61]. We now investigated intensity coding of the same adequate stimulus at different system levels, facilitating translation of peripheral encoding of noxious heat pain from cellular 
models to human experiments using a specific non-damaging noxious heat stimulus.

The capsaicin receptor TRPV1 has been described as a cation channel gated by noxious heat [10]. Phosphorylation by different kinases (PKA, PKC, MAPK), mirrors peripheral sensitization to heat by inflammatory mediators [25] and the resulting primary hyperalgesia following injury $[9,10,13]$. The competitive TRPV1 antagonist capsazepine (CPZ) inhibits heat-induced inward currents in TRPV1-expressing cells [10] and nociceptive neurons $[31,34]$. While mice with depleted TRPV1 carrying nerve fibers selectively lose heat sensitivity [11], TRPV1 knockout mice still have behavioral sensitivity to ramped heat stimuli $[9,13]$. Two additional TRP channels, TRPM3 and TRPA1, seem to contribute to the perception of heat pain [60]. The lack of an acute heat phenotype when knocking out TRPV1 may be explained by absence of functional relevance for acute pain or by mismatch of heat stimulus characteristics and TRPV1 thermal gating properties. Until now, there is a mismatch of stimulation paradigms between recent molecular, electrophysiological and behavioural studies of heat pain. Contact heat stimuli are applied by thermodes in human and animal studies [12, $16,60]$, while at the cellular and molecular level superfusion with heated solutions is used [52, 60]. Radiant heat stimuli that allow precise control of stimulus timing, are considered gold standard for clinical electrophysiological studies of heat pain pathways [23] but are rarely used in vitro [19, 27, 64]. Infrared lasers have been used in a few studies on animal behaviour $[1,8,39,63]$, electrophysiology $[14,56,58]$, dorsal root ganglion (DRG) neurons [19, 40] and heterologously expressed TRPV1 [27, 64]. Wavelengths of these lasers, however, range between 980 and $10,600 \mathrm{~nm}[19,59]$, spot sizes between 0.1 and $10 \mathrm{~mm}$ [27, 41] and pulse durations between 3 and $400 \mathrm{~ms}[19,53]$, making comparisons across studies difficult.

The aim of this study was to facilitate the direct translation of peripheral encoding of noxious heat from cellular models to human experiments using the same near-infrared laser stimuli in three system levels. Encoding properties of transient, non-damaging laser heat stimuli will be characterized in human psychophysics and rat DRG neurons and compared to heterologously transfected HEK293 cells. Involvement of TRPV1 in signal transduction will be compared between native neurons and a heterologous expression system regarding thresholds, suprathreshold encoding, strength-duration curves and tachyphylaxis.

\section{Materials and methods}

Two diode lasers were used with wavelengths near an absorption peak in water and thus approximately in skin $(\lambda=1470 \mathrm{~nm} / 1475 \mathrm{~nm}$; see Fig. 1a; $[43,64])$.
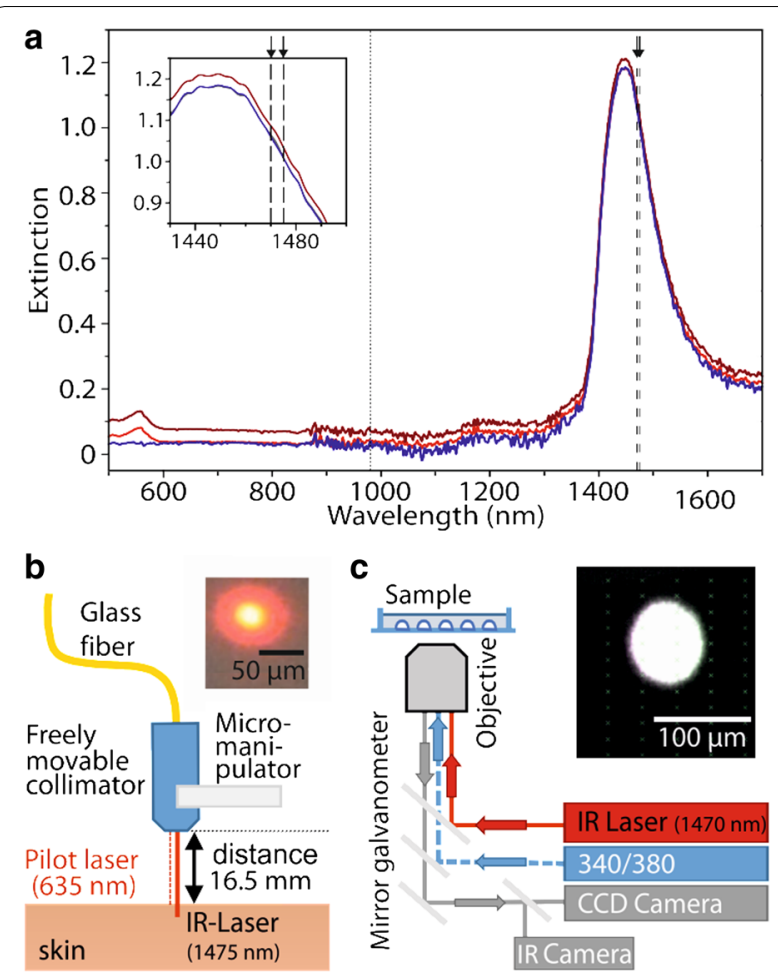

Fig. 1 Setups for diode laser heat stimulation in vivo and in vitro. a Absorption spectra of water (blue), DMEM F12 medium (red) and DRG neurons suspended in DMEM F12 medium (dark red). DMEM F12 with-/without neurons had an absorption peak near $550 \mathrm{~nm}$ due to phenol red, suspended neurons induced a slight parallel upwards shift of absorption spectrum due to scattering. Wavelengths of our two diode lasers near the absorption peak of water $(1450 \mathrm{~nm})$ are indicated as dashed lines. Inset shows the almost identical absorption of the slightly different wavelengths used (arrows). Wavelength of a laser used previously is marked with dotted line [19]. b Schematic view of set-up for studies in humans. A pilot laser $(635 \mathrm{~nm})$ is used for aiming at the skin surface (see inset); the $1475 \mathrm{~nm}$ laser radiation has its focus $930 \mu \mathrm{m}$ below skin surface. c Schematic view of integrated laser stimulation set-up for cell physiology experiments. The diode laser (DL-1470; "IR Laser") is coupled into an inverted microscope via a beam splitter and focused to the image plane of the microscope. Mirror galvanometers move the laser beam to excite cells directly without any absorbance by aqueous solution. Aiming is verified by an infrared camera on the microscope (see inset)

Both lasers were focused to a small diameter (nominally 100 or $150 \mu \mathrm{m}$ ), allowing for rapid passive cooling and selective activation of single cells on a microscope cover slip as only a very small volume is heated. Extinction spectra of DRG neurons in F12 medium were measured in $10 \mathrm{~mm}$ quartz glass cuvettes from 500 to $2200 \mathrm{~nm}$ in triplicates, using an Excalibur Series FTS 3000 Infrared Spectrometer (BioRad, Munich, Germany). 


\section{In vivo model: humans}

\section{Diode laser stimulation in humans}

On hairy skin of the dorsal side of hands and feet heat stimuli were applied with a focused diode laser stimulator with a nominal maximum power of $100 \mathrm{~mW}$, and a diameter of $150 \mu \mathrm{m}$ on skin surface at $1475 \mathrm{~nm}$ (LaserdiodenStrahlquelle SK9-2001; Schäfter + Kirchhoff, Hamburg, Germany). An integrated pilot laser with a wavelength of $635 \mathrm{~nm}$ was used for focusing by keeping the distance between fibre tip and skin constant; thereby maximum heating of skin layers below surface was achieved (see Fig. 1b).

The laser used in humans in vivo was focused to $930 \mu \mathrm{m}$ below skin surface, using a difference in focal length between the visible pilot laser (focused on the skin surface to indicate the stimulus location; see inset in Fig. 1b) and the near infrared stimulation laser to heat the epidermis and dermis (Fig. 2a). To characterize the steep ramped laser stimuli in humans, thermographic measurements of the effective temperature were performed using an infrared thermocamera (PI 640 with microscope optics, Optris, Berlin, Germany) with Optris PI Connect software (Rel. 2.3) at an acquisition frame rate of $125 \mathrm{~Hz}$. We recorded from the surface of human skin on the dorsal hand, as well as surface and side view (Fig. 2b-d) of a $4 \%$ agar model for skin [47] to monitor temperature changes at deeper layers in Z-direction (Fig. 2e) and to determine temporal stimulus characteristics (Fig. 2f-h). Laser heat profiles developed according to the Gaussian beam profile (Fig. 2b-d) and temperature maxima were about $280 \mu \mathrm{m}$ below surface (Fig. $2 \mathrm{~b}$, e). Additionally to the intraepidermal nerve fibers that are evaluated clinically, there is also a dense network of nerve fibers within this depth range (insert in Fig. 2a). Temperature rose nearly exponentially at the surface of the skin (Fig. 2h), the surface of an agar phantom (Fig. 2g) and at $280 \mu \mathrm{m}$ below the agar surface (up to $320^{\circ} \mathrm{C} \mathrm{s}^{-1}$; Fig. 2f). Passive cooling was exponential with a time

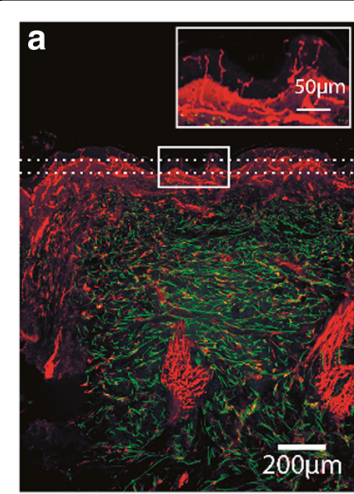

e

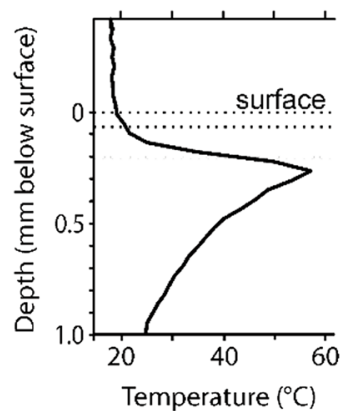

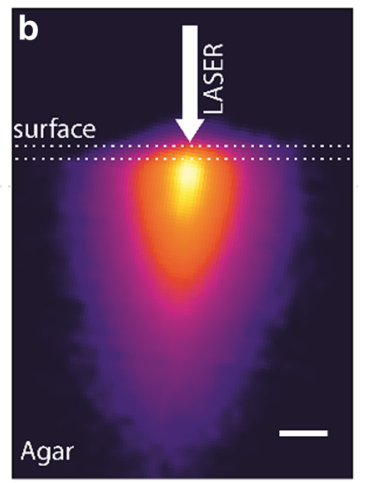

f

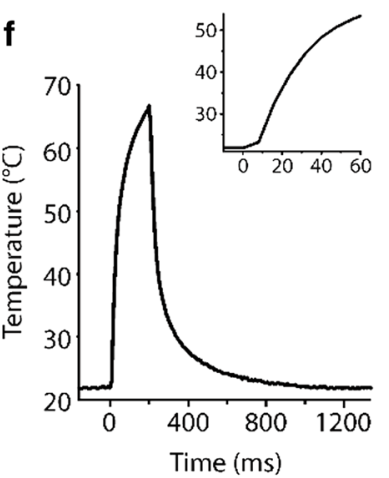

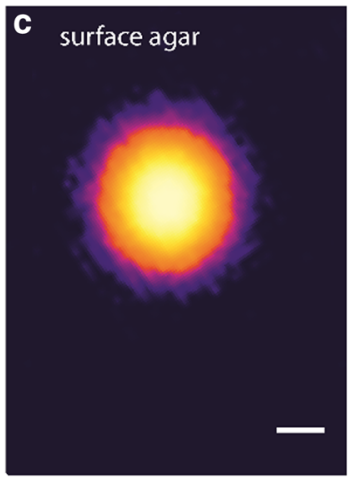

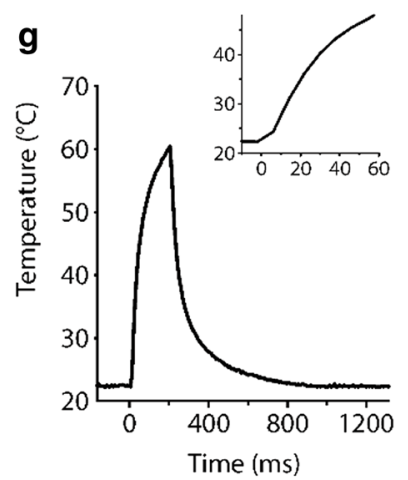

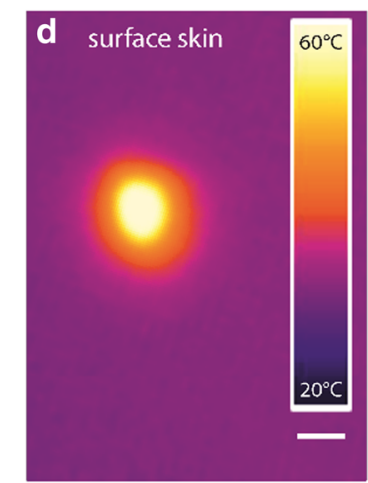

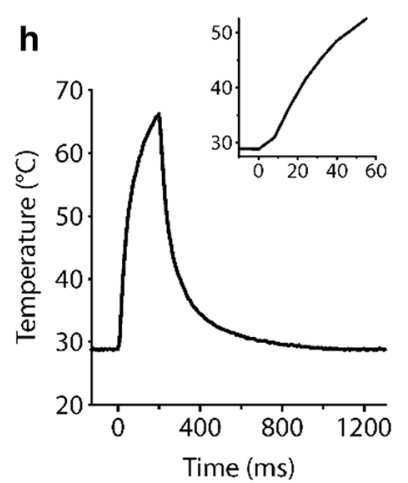

Fig. 2 Focused diode laser stimuli rapidly increase temperature within a small volume of human skin. a Histology of human skin stained for the neuronal marker PGP9.5 to display free epidermal and dermal nerve endings in red color (skin biopsy kindly provided by Claudia Sommer, Würzburg). Dashed lines indicate approximatively borders of epidermis/dermis and dermis to facilitate comparison to agar model in (b). Insert shows intraepidermal fibers at higher resolution. b Spatial distribution of temperature changes with a Gaussian distribution as a consequence of a laser stimulus (100 mW, $200 \mathrm{~ms}$ ) using agar as a model of human skin (side view with thermocamera Optris PI 640). The heated volume is small and the maximum heating is achieved at about $280 \mu \mathrm{m}$ depth. $\mathbf{c}$ Temperature distribution on the surface of the agar model and $\mathbf{d}$ on the skin surface of the human hand dorsum. e Thermoprofile of (b) confirming the maximum temperature at about $280 \mu \mathrm{m}$ below surface, dotted lines as in (a, b). $\mathbf{f}-\mathbf{h}$ Time courses of temperature changes due to a single laser stimulus obtained from the experiments shown in (b-d), inset in (f-h) display magnification to visualize threshold temperatures. Scale bars in (a-d) $200 \mu \mathrm{m}$ 
constant of $\tau=0.35 \pm 0.01$ s on skin, $0.29 \pm 0.01 \mathrm{~s}$ on agar and $0.32 \pm 0.01 \mathrm{~s}$ beneath surface (Fig. 2f-h). No heat accumulation was measurable for interstimulus intervals (ISIs) $\geq 1 \mathrm{~s}$. Peak temperature increase was $37.8 \pm 0.5{ }^{\circ} \mathrm{C}$ above baseline (Fig. 2f) for this strong suprathreshold stimulus (200 ms, $100 \mathrm{~mW})$. Baseline temperature in hands was $29.8 \pm 0.5^{\circ} \mathrm{C}$, in feet $26.7 \pm 1.2^{\circ} \mathrm{C}$.

\section{Human psychophysics}

Experiments were performed in healthy human volunteers $(n=10 ; 3$ female, 7 males, age $21-30$ years, $25.7 \pm 2.5$ mean $\pm \mathrm{SD}$ ). All volunteers gave written informed consent after careful explanation of the nature and possible consequences of the studies; the experiments were approved by the local ethics committee. Laser pulses of different durations (range: 5-390 ms, at least 5 stimuli per duration and side) were applied at constant power of $100 \mathrm{~mW}$ to the dorsum of the hands and feet. Even with maximum duration $(390 \mathrm{~ms})$ no side effects other than small, slight and transient red spots were observed, particularly no burn injury. Painfulness was assessed using a numeric rating scale (NRS) ranging from 0 (=no pain) to 100 (=strongest imaginable pain). Pain thresholds were determined as the minimum stimulation duration inducing a painful hot or pinprick-like sensation, using a staircase regime (method of limits). The site of stimulation was slightly changed after each stimulus in order to avoid nociceptor suppression and tachyphylaxis of $I_{\text {heat }}[33,52]$. To quantify tachyphylaxis, in separate experiments the same spot was stimulated repeatedly [17] at an interstimulus interval (ISI) of $180 \mathrm{~s}$ like in the in vitro experiments.

\section{Desensitization of TRPV1-expressing nerve fibers}

Adhesive skin patches containing 8\% capsaicin (Qutenza ${ }^{\circledR}$, Astellas Pharma, Munich, Germany) were applied on the dorsal side of one hand and one foot for $24 \mathrm{~h}$ in an area of about $3 \times 3 \mathrm{~cm}$ to reversibly desensitize TRPV1-expressing nerve terminals in the skin [24]. On the contralateral area, a vehicle patch without capsaicin was used as a control (Qutenza ${ }^{\circledR}$ Demo, Astellas). Numeric pain ratings and threshold determination in test and control areas were compared before and after application of the patches.

\section{Data analyses}

All NRS ratings were $\log _{10}$-transformed after addition of a constant of 0.1 to avoid loss of zero ratings, in order to obtain secondary normal distribution of rating data. All data are shown as mean \pm standard error of the mean (SEM) if not otherwise indicated. Effects were statistically analysed for significance using paired or unpaired Student's t-test and analysis of variance (ANOVA; Statistica
4.5, StatSoft Inc., Tulsa, OK, USA), $\mathrm{p}<0.05$ was considered significant.

\section{In vitro models \\ DRG cell culture}

Acutely dissociated dorsal root ganglion (DRG) neurons were obtained as follows. Animals' care was in accordance with institutional guidelines and approved by the appropriate authorities. Male adult Sprague-Dawley rats (4-8 weeks old, 280-350 g; Janvier, Le Genest-SaintIsle, France) were deeply anesthetized with isoflurane (Forene ${ }^{\circledR}$, Abbvie Deutschland, Wiesbaden, Germany), and rapidly decapitated. Spine was removed and chilled on ice in Dulbecco's modified Eagle's medium (DMEM) F12 medium (Sigma-Aldrich, Munich, Germany) containing $26 \mathrm{mM} \mathrm{NaHCO}$ (Roth, Karlsruhe, Germany), $100 \mathrm{IU} \mathrm{ml}^{-1}$ penicillin, $100 \mu \mathrm{g} \mathrm{ml}^{-1}$ streptomycin (Gibco, Darmstadt, Germany) and equilibrated with $95 \% \mathrm{O}_{2}$ and $5 \% \mathrm{CO}_{2}$. Neurons were incubated in collagenase CLS II (10 $\mathrm{mg} \mathrm{ml}^{-1}$; Biochrome, Berlin, Germany) and accutase (1x; Sigma Aldrich) for $45-60 \mathrm{~min}$ at $37{ }^{\circ} \mathrm{C}$, washed trice with medium, triturated with fire polished pasteur pipettes and resuspended in neurobasal medium (Invitrogen, Darmstadt, Germany) containing 2\% horse serum (Gibco), B27 (Gibco), Pen/Strep (100 $\mathrm{IU} \mathrm{ml}^{-1}$ penicilline, $100 \mu \mathrm{g} \mathrm{ml}^{-1}$ streptomycin; Gibco), $200 \mathrm{mM}$ L-glutamine (Gibco) and NGF (50 ng ml ${ }^{-1}$; Gibco). Then they were plated on microscope cover slips (Ø $15 \mathrm{~mm}$, transparent to $1470 \mathrm{~nm}$ laser; Roth), coated with laminin $(1.5 \mu \mathrm{g} /$ cover slip; Sigma-Aldrich). Finally, the neurons were stored in a humidified $5 \% \mathrm{CO}_{2}$-atmosphere at $34{ }^{\circ} \mathrm{C}$ before being used within $24 \mathrm{~h}$.

\section{HEK293 cell culture}

Human embryonic kidney (HEK293) cells were cultured in DMEM (Gibco) supplemented with 10\% fetal calf serum (FCS Gold, Gibco), $100 \mathrm{IU} \mathrm{ml}^{-1}$ penicillin, $100 \mu \mathrm{g} \mathrm{ml}^{-1}$ streptomycin (Gibco) in a humidified 5\% $\mathrm{CO}_{2}$-atmosphere at $37{ }^{\circ} \mathrm{C}$. One day prior to transfection, cells (with a density of 100-400,000 cells/well in a 12-well plate) were seeded on poly-L-lysine-covered $\left(10 \mu \mathrm{g} \mathrm{ml}^{-1}\right.$, Sigma-Aldrich) microscope cover slips (Ø $15 \mathrm{~mm})$ and transfected using $6 \mu \mathrm{l}$ nanofectamine (PAA, Pasching, Austria), $1 \mu \mathrm{g}$ rat TRPV1 for comparison with rat DRGs and $1 \mu \mathrm{g}$ pTagGFP (100 $\mu \mathrm{l}$ per coverslip; cf. [37]) for fluorescent identification of transfected cells. Within $48 \mathrm{~h}$ after transfection cells were used for functional calcium imaging.

\section{Calcium imaging}

For measurements of free intracellular calcium $\left(\left[\mathrm{Ca}^{2+}\right]_{\mathrm{i}}\right)$ the cells were loaded with $3 \mu \mathrm{M}$ (HEK) or $1 \mu \mathrm{M}$ (DRG) of the fluorescent calcium indicator FURA-2AM $(1 \mathrm{mM}$ 
in DMSO, Biotrend, Cologne; Germany) and $1 \mu \mathrm{l} \mathrm{Plu-}$ ronic F-127 (10\% in DMSO, Calbiochem, Darmstadt, Germany) for 45-60 min (HEK) and $30 \mathrm{~min}$ (DRG) in Tyrode's solution containing $137.6 \mathrm{mM} \mathrm{NaCl}, 5.4 \mathrm{mM}$ $\mathrm{KCl}, 0.5 \mathrm{mM} \mathrm{MgCl}_{2}, 1.8 \mathrm{mM} \mathrm{CaCl}, 10 \mathrm{mM}$ HEPES and $5 \mathrm{mM}$ glucose (adjusted to $\mathrm{pH} 7.3$ with $\mathrm{NaOH}$; Roth). After washing them trice with Tyrode's solution and at least 20 min resting, cover slips were mounted in an open bath chamber (Series 40 Quick Change Imaging Chamber; Warner Instruments, Hamden, USA) on an inverted microscope (Olympus IX81; Olympus, Tokyo, Japan) equipped with an image acquisition and analysis system (xcellenceRT; Olympus) and superfused with Tyrode's solution $\left(\sim 2 \mathrm{ml} \mathrm{min}^{-1}\right)$. Cells were illuminated alternatingly with light of 340 and $380 \mathrm{~nm}$ wavelength $(\geq 0.5 \mathrm{~Hz})$ and the respective fluorescent signals at $510 \mathrm{~nm}$ were detected by an ORCA-R2 CCD camera (Hamamatsu Photonics, Hamamatsu, Japan; scheme see Fig. 1c). The ratio of fluorescence emission at $510 \mathrm{~nm}$ for excitation at 340 vs $380 \mathrm{~nm}$ excitation was used as relative change in $\left[\mathrm{Ca}^{2+}\right]_{\mathrm{i}}[22]$. All experiments were carried out at room temperature.

\section{Diode laser stimulation in vitro}

A computer controlled near infrared laser (DL-1470, $1470 \mathrm{~nm}$ wavelength, max. power $10 \mathrm{~W}$; Rapp OptoElectronic, Wedel, Germany) yielding effectively up to $460 \mathrm{~mW}$ output power, focused to a diameter of nominally $100 \mu \mathrm{m}$ (Gaussian distribution, $1 / \mathrm{e}=70 \mu \mathrm{m}$; objective UApo/340 20x/0.75, Olympus) was coupled into the microscope via an optical bench and a scanning system (UGA-40, Rapp; Fig. 1c). For adjustment of the laser, a CCD camera with an IR-sensitive InGgAs (photo)sensor (IR camera, Rapp; NI-IMAQ, National Instruments, Munich, Germany) was placed in a parallel optical port of the microscope and the system was aligned with the images obtained in calcium imaging. Hence, aiming at single or small groups of cells (depending on the cell density) on a microscope cover slip during one experiment was possible using the scanning system driven by SysCon software (Rapp). Stimulus intensity was changed by varying laser power (13-460 $\mathrm{mW}$ ) and/or stimulus duration (1-300 ms).

The laser used in cell physiology experiments in vitro was focused to the bottom of the cover slips, where DRG neurons or HEK cells had been plated. Stimulus location was observed via the infrared camera integrated in the microscope (Fig. 1c). Spot size of the area irradiated by IR-laser light as measured using this camera was $74 \mu \mathrm{m}$ (1/e, inset in Fig. 1c). The size of the heated area was measured using thermosensitive molecular beacons that increase their fluorescence with increasing temperature (Fig. 3A-C; [29]). The spatial temperature profile was bell-shaped with a 1/e spot diameter of $61 \mu \mathrm{m}$. The spatial pattern of laser heat responses was determined using densely plated TRPV1 transfected HEK cells and showed an activated area of about $100 \mu \mathrm{m}$ in diameter, again with a bell-shaped curve of intensities (Fig. 3D-F). Only cells within the laser heated area (i.e. 1/e radius according to the determined diameter) responded (Fig. 3D, E) indicating high spatial resolution. In conclusion, our laser system provides a precise means for stimulation of selected cells with high spatial and temporal resolution.

In order to characterize the heating pattern of the laser and taking the temporal resolution of the live cell imaging system into account, we applied stimuli of $200 \mathrm{~ms}$ in a suspension of $0.85 \mathrm{nM}$ L-DNA thermosensitive molecular beacons [29] in Tyrode's solution while measuring fluorescence intensity with the maximum possible acquisition frame rate of $10 \mathrm{~Hz}$. Tachyphylaxis was tested with an ISI of $180 \mathrm{~s}$. During the experiments over time spans of up to $45 \mathrm{~min}$, no significant cell degradation attributable to diode laser irradiation was observed.

\section{Chemicals}

Capsaicin and capsazepine (CPZ; Sigma-Aldrich) were dissolved in ethanol and DMSO as stock solutions (100 mM and $10 \mathrm{mM}$ ), stored at $4{ }^{\circ} \mathrm{C}$. Capsaicin, $\mathrm{CPZ}$ and ionomycin (1 mM stock solution in DMSO, Calbiochem) were dissolved in Tyrode's solution to a final concentration of $10 \mu \mathrm{M}$ shortly before each experiment. The drugs did not change the $\mathrm{pH}$ of the solutions by more than 0.1 and maximum ethanol concentration was $0.1 \%$.

\section{Data analysis}

Analysis of ratios of emission intensity at $340 \mathrm{~nm} / 380 \mathrm{~nm}$ excitation and subtraction of background fluorescence were carried out off line with xcellenceRT software (Olympus). All cells within the 1/e diameter of the laser heated area (cf. Fig. 3F) were marked individually as regions of interest (ROIs; $12-150$ per experiment), corresponding to the examined cells. The number of cells is given (n). Transfected HEK cells were considered TRPV1 positive only when responding to $10 \mu \mathrm{M}$ capsaicin. DRG neurons were tested for viability and excitability by depolarisation using high potassium solution $(140 \mathrm{mM} \mathrm{KCl})$.

Relative change of fluorescence ratio was calculated by dividing the peak value by the preceding baseline. An increase of $\geq 23 \%$ was regarded as a significant response [18]. Thresholds were defined as the necessary stimulus duration at a certain fixed intensity or the necessary stimulus intensity at a certain fixed duration that induced a significant increase in intracellular calcium in $50 \%$ of the stimulated cells ( $\mathrm{T}_{50}$ of sigmoidal fitted responder curve). All data are shown as mean \pm standard error of the mean (SEM). Effects were statistically analysed for significance 

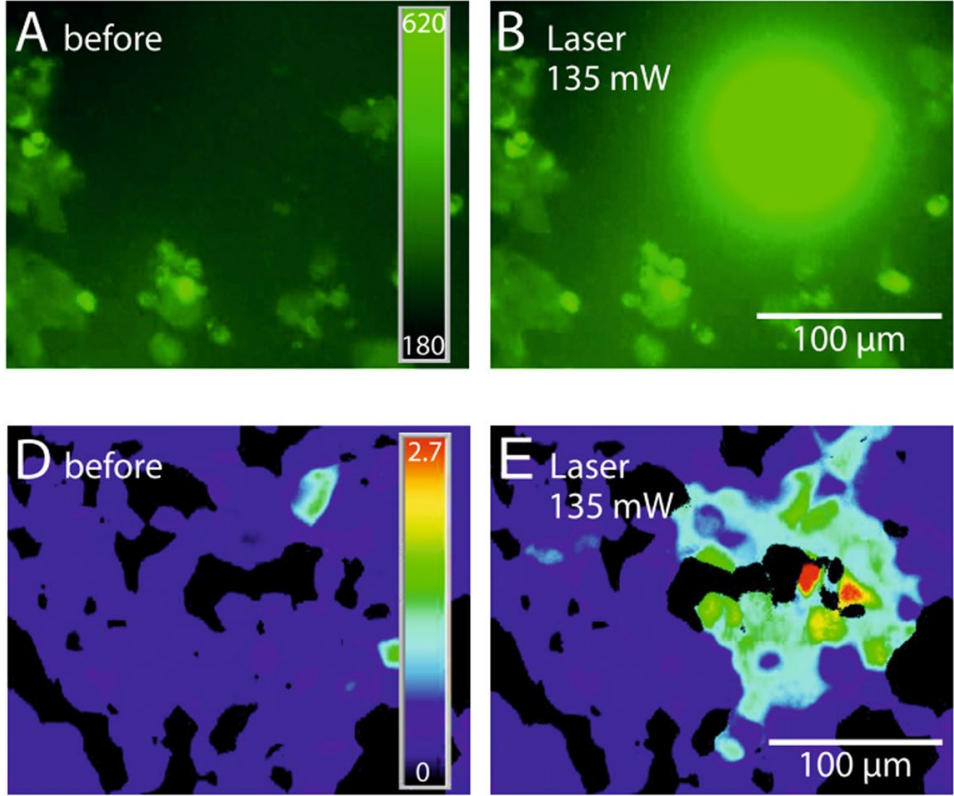

Fig. 3 Focused diode laser stimuli rapidly increase temperature at the bottom of a cell culture dish. A-C Photothermal study using temperature-sensitive L-DNA beacons suspended in Tyrode's solution with GFP transfected HEK cells for size comparison. A laser pulse of 135 mW for 200 ms induces a fluorescence signal with a Gaussian spatial distribution (C). Dotted red lines indicate 1/e of maximum used to determine spot diameter $(60 \mu \mathrm{m})$. D-F Ratiometric microfluorimetry of calcium transients in HEK cells transfected with TRPV1 and loaded with FURA-2. The calcium response profile of responding cells reflects the spatial heating pattern (F), dotted red lines indicate 1/e diameter. This diameter (about $100 \mu \mathrm{m})$ was used for definition of ROls within laser radiated area

using two-tailed paired or unpaired Student's t-test, $\mathrm{p}<0.05$ was considered significant.

\section{Results}

\section{Characterization of laser stimuli}

Extinction spectra of visible light and near infrared radiation showed the known absorption peak of water at $1450 \mathrm{~nm}$ (Fig. 1a, blue trace). DMEM F12 medium (light red) and neuronal cell suspension in DMEM F12 medium (dark red) displayed an additional peak around $550 \mathrm{~nm}$, caused by the $\mathrm{pH}$ indicator phenol red. A parallel upward shift of the complete extinction spectrum was observed with suspended cells, due to scattering. In the near-infrared range, principally, scattering and absorption by biomolecules is by far exceeded by absorption in water [26]. As our data did not show any specific absorption bands of DRG neurons and absorption by water determines radiant heat energy deposition in nociceptive neurons and nerve terminals, absorption characteristics of neuronal cells can be considered the same as of water. Thus, wavelengths to heat neurons in the near IR ideally are near the absorption peaks of water. We therefore used near infrared laser stimuli of nearly identical wavelengths (1470 and 1475 nm; see enlarged inset in Fig. 1a), to stimulate human skin (Fig. 1b) and cells within the microscope (Fig. 1c).

When focused to $930 \mu \mathrm{m}$ below human skin surface, laser stimuli rapidly heated nociceptive nerves within epidermis and dermis (Fig. 2a; up to $320{ }^{\circ} \mathrm{C} \mathrm{s}^{-1}$; Fig. 2f) with temperature maxima at about $280 \mu \mathrm{m}$ below surface (Fig. 2b, e). In addition to the intraepidermal nerve fibers that are evaluated clinically, there is also a dense network of dermal nerve fibers within this depth range (insert in Fig. 2a). Heat sensitive nociceptors are located between 20 and $570 \mu \mathrm{m}$ below skin surface [54]. Peak temperature increase above baseline was $37.8 \pm 0.5^{\circ} \mathrm{C}$ (Fig. 2f) for strong suprathreshold stimulation $(200 \mathrm{~ms}, 100 \mathrm{~mW})$ reaching noxious temperatures within about $25 \mathrm{~ms}$ without any heat accumulation for interstimulus intervals (ISIs) $\geq 1 \mathrm{~s}$. Baseline temperature in hands was $29.8 \pm 0.5{ }^{\circ} \mathrm{C}$, in feet $26.7 \pm 1.2{ }^{\circ} \mathrm{C}$. Temperature rapidly returned by passive cooling [time constant $\tau=0.35 \pm 0.01 \mathrm{~s}$ on skin, $0.29 \pm 0.01 \mathrm{~s}$ on agar and $0.32 \pm 0.01 \mathrm{~s}$ beneath surface (Fig. $2 \mathrm{f}-\mathrm{h}$ )].

The laser stimulator embedded in the live-cell imaging microscope (diameter of irradiated spot about $74 \mu \mathrm{m})$ induced a bell-shaped spatial temperature profile with an 1/e spot diameter of $61 \mu \mathrm{m}$ (inset in Fig. 1c) as 
characterized using thermosensitive molecular beacons (Fig. 3A-C; [29]). Using densely plated TRPV1 transfected HEK cells, laser heat responses were seen with a bell-shaped curve of response magnitudes within an area of about $100 \mu \mathrm{m}$ in diameter, (Fig. 3D-F) but not outside, indicating high spatial resolution. In conclusion, our laser system provides a precise means for stimulation of selected cells with high spatial and temporal resolution.

\section{Diode laser heat pain in humans is encoded by TRPV1-expressing neurons}

When stimulated with suprathreshold laser pulses, all human subjects $(n=10)$ reported a first clear, pricking pain sensation followed by a second more diffuse, burning pain, which is consistent with the activation of $A \delta$ and C-fibers. Pain thresholds at the hand $(25.9 \pm 2.6 \mathrm{~ms}$ at $100 \mathrm{~mW}$ laser power, $2.6 \mathrm{~mJ}$, about $22.3^{\circ} \mathrm{C}$ increase [from inset Fig. 2f]) were significantly lower than at the foot $\left(42.6 \pm 5.1 \mathrm{~ms}, 4.3 \mathrm{~mJ}\right.$, about $28.3{ }^{\circ} \mathrm{C}$ increase (Fig. 2f); p <0.01, unpaired t-test, Fig. 4a; method of limits). In single subjects, stimuli were perceived as painful down to a minimal stimulation duration of $6 \mathrm{~ms}(0.6 \mathrm{~mJ}$, about $7.6{ }^{\circ} \mathrm{C}$ increase [from Fig. 2f]). Incidence of painful trials increased with stimulus duration following sigmoidal functions (Fig. $4 \mathrm{~b}, \mathrm{c}$ ); $50 \%$ thresholds $\left(\mathrm{T}_{50}\right)$ were found to be $28.6 \pm 0.8 \mathrm{~ms}$ (about $23.5^{\circ} \mathrm{C}$ increase) at the hand and $43.7 \pm 3.6 \mathrm{~ms}$ (about $28.6{ }^{\circ} \mathrm{C}$ increase) at the foot. Suprathreshold ratings showed a linear increase of perceived pain intensity in double logarithmic space with exponents of 1.1 to 1.2 (Fig. $4 \mathrm{~d}$, e; $\mathrm{r}^{2}$ of linear fits 0.97-0.99).

After complete desensitization of TRPV1-expressing skin nerve fibers by topical application of $8 \%$ capsaicin patch for $24 \mathrm{~h}\left(\mathrm{Qutenza}^{\circledR}\right)$, laser induced heat pain was completely abolished (filled circles in Fig. 4d, e) and heat pain threshold was not detectable within the tested stimulus durations (up to $390 \mathrm{~ms}, 100 \mathrm{~mW} ; \mathrm{p}<0.001$ test vs. control area; see Fig. 4a). These results suggest that these laser pulses induced heat pain by activation of TRPV1expressing neurons.

\section{Sensitivity to laser heat is co-expressed with capsaicin sensitivity in DRG neurons and TRPV1-expressing HEK cells} Figure 5 shows cellular response patterns to laser heat and capsaicin stimulation of all cells at least once irradiated by laser (within 1/e diameter, see Fig. 2f). In 290 of 354 tested DRG neurons (82\%) an increase of intracellular calcium $\left(\left[\mathrm{Ca}^{2+}\right]_{\mathrm{i}}\right)$ in response to capsaicin $(10 \mu \mathrm{M})$ was observed, indicating their native TRPV1-expression (Fig. 5a). Sensitivity to capsaicin and heat were significantly co-expressed: 262/290 (89\%) of TRPV1-expressing neurons were heat sensitive and 262/264 (99\%) heat sensitive neurons were capsaicin sensitive (Cohen's Kappa
$0.75, \mathrm{p}<0.001)$. It has to be noted that laser stimuli were of moderate intensity to avoid cell damage and cells at beam perimeter (within 1/e radius) were included in the analysis.

In TRPV1 transfected HEK cells, 1203 of 1543 (78\%) were considered successfully transfected [increase of $\left[\mathrm{Ca}^{2+}\right]_{i}$ when stimulated with capsaicin $\left.(10 \mu \mathrm{M})\right]$ (Fig. 5b). Of those, 1068 (89\%) were also laser heat sensitive. Of the 1104 cells sensitive to heat 1068 (97\%) were also sensitive to capsaicin $(10 \mu \mathrm{M})$. Thus, sensitivity to heat and capsaicin were highly correlated (Cohen's Kappa $0.71, \mathrm{p}<0.001)$. Hence, expression of TRPV1 transfers laser heat sensitivity to non-excitable HEK cells. In cells only transfected with GFP but not TRPV1, a small fraction (25/722: $3.5 \%)$ did show a slight increase of $\left[\mathrm{Ca}^{2+}\right]_{\mathrm{i}}$ to laser heat stimuli (Fig. 5c).

Responder rates increased as a function of stimulus duration in a sigmoidal fashion in both cell types, like in the in vivo experiments in humans (Fig. $5 \mathrm{c}$ ). The $\mathrm{T}_{50}$ responder threshold in HEK cells $(3.8 \mathrm{~ms}$ at $135 \mathrm{~mW}$, $0.52 \mathrm{~mJ}, \mathrm{n}=213$ ) was slightly lower than in DRG neurons ( $4.2 \mathrm{~ms}$ at $135 \mathrm{~mW}, 0.56 \mathrm{~mJ}, \mathrm{n}=115$ ), and the response magnitude higher at $5 \mathrm{~ms}$ stimulus duration $(82 \%$ vs. $42 \%$ above baseline), but across all stimulus durations the response magnitudes did not differ significantly (ANOVA, main effect of cell type: $\mathrm{F}_{(1,807)}=1.19, \mathrm{p}=0.28$ ). Both cellular thresholds were markedly lower than $\mathrm{T}_{50}$ thresholds in humans at $100 \mathrm{~mW}(28.6 \pm 0.8 \mathrm{~ms}$ at the hand), suggesting that substantial summation in the central nervous system (CNS) is necessary for laser heat pain perception.

\section{Encoding of the intensity of laser heat pulses by TRPV1 transfected HEK cells}

Stimulus durations as short as $1 \mathrm{~ms}$ were sufficient to evoke significant responses in 17 out of 81 TRPV1 transfected HEK cells tested at $190 \mathrm{~mW}(21 \%$, see Fig. 6a for a representative example). $\mathrm{T}_{50}$ threshold durations increased with decreasing laser power: $1.7 \mathrm{~ms}$ at $190 \mathrm{~mW}$ $(0.32 \mathrm{~mJ}, \mathrm{n}=150), 3.8 \mathrm{~ms}$ at $135 \mathrm{~mW}(0.52 \mathrm{~mJ}, \mathrm{n}=213)$ and $8.4 \mathrm{~ms}$ at $80 \mathrm{~mW}(0.67 \mathrm{~mJ}, \mathrm{n}=142$; Fig. $6 \mathrm{~b})$. Using a fixed stimulation duration of $5 \mathrm{~ms}, \mathrm{~T}_{50}$ threshold was $103.8 \mathrm{~mW}$ (0.52 mJ, n=666; Fig. 6c). The efficacy for the induction of laser heat responses in TRPV1-expressing cells never reached $100 \%$ (Fig. 6b, c), possibly due to cells at the perimeter of the laser beam. In double-logarithmic scaling, stimulus-response functions were linear but seemed to show saturation at higher stimulus durations. At the highest laser power of $190 \mathrm{~mW}$ the Stevens' exponent of 0.85 (slope) nearly matched those of our human pain perception data (exponents of 1.1 to 1.22 , Fig. $4 \mathrm{~d}$, e). Those of lower laser powers ( $80 \mathrm{~mW}: 0.52,135 \mathrm{~mW}$ : 0.4; Fig. $6 \mathrm{~d})$ and at a constant stimulus duration $(5 \mathrm{~ms}$ : 0.62 ; 

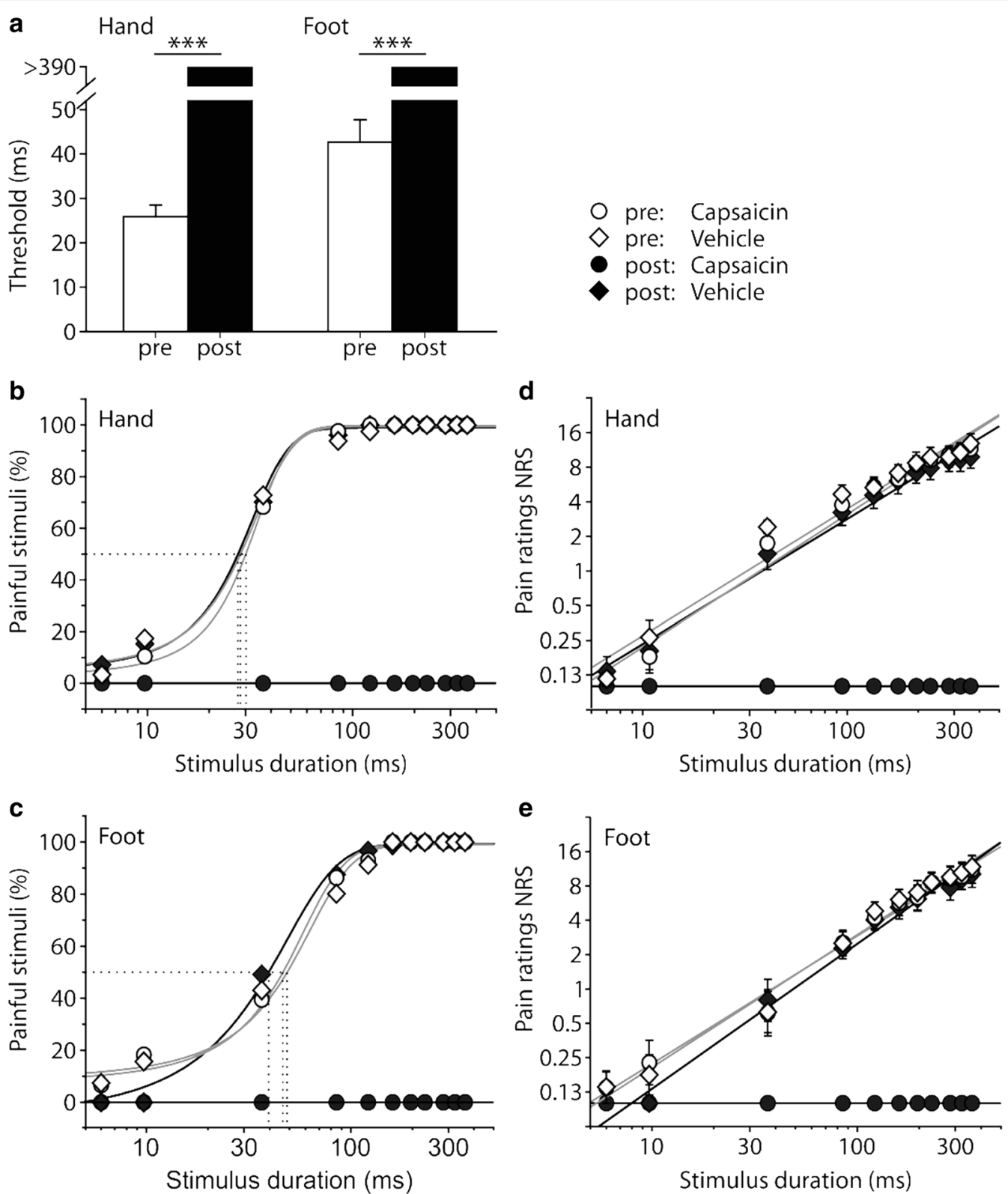

Fig. 4 Human diode laser induced heat pain depends on TRPV1-expressing nerve fibers. a Mean pain thresholds (stimulus duration at $100 \mathrm{~mW}$ ) on hand and foot $(n=10)$. After desensitization by $8 \%$ capsaicin for $24 \mathrm{~h}\left(\right.$ Qutenza $\left.{ }^{\circledR}\right)$, laser heat pain sensations were abolished and stimuli were not perceived even at maximum stimulus duration (390 ms) and laser power (100 mW); ${ }^{* * *} p<0.001$, paired t-test. b, c Psychometric functions (\% painful stimuli) before (open symbols) and after (filled symbols) capsaicin (circles) or vehicle patch application (diamonds) for $24 \mathrm{~h}$. $\mathrm{T}_{50}$ values indicated as dotted lines. $\mathbf{d}$-e Pain ratings displayed a linear increase in double logarithmic coordinates following a power function with an exponent of 1.1 at the hand and 1.2 at the foot. Pain perception was completely abolished after TRPV1 desensitization by application of a capsaicin patch for $24 \mathrm{~h}$ (filled circles)

Fig. 6e) were slightly smaller. We did not increase laser power beyond $190 \mathrm{~mW}$, as we wanted to avoid cell damage and non-specific responses.

Saturation in calcium signals was seen earlier than in human pain psychophysics. This might be due to saturation of calcium influx from extracellular space: whereas fluorescence ratio at equilibrium with extracellular calcium $(10 \mu \mathrm{M}$, ionomycin superfusion) reached $3.04 \pm 1.34$, calcium transients through TRPV1 $(10 \mu \mathrm{M}$ capsaicin as supramaximal dose) saturated at $1.54 \pm 0.95$ and the maximum laser heat-induced calcium transients were limited to $1.29 \pm 0.61(190 \mathrm{~mW}, 4 \mathrm{~ms}, \mathrm{n}=235, \pm S D)$. 
a

Native DRG neurons $(n=354)$

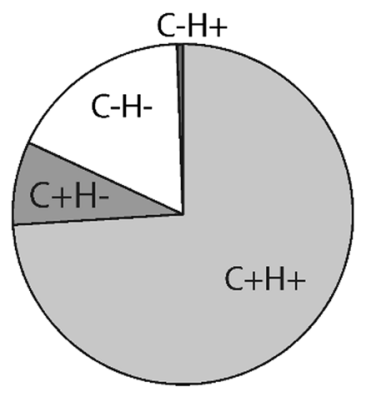

b TRPV1 transfected HEK cells $(n=1543)$

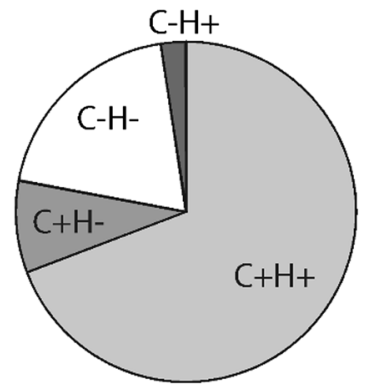

C

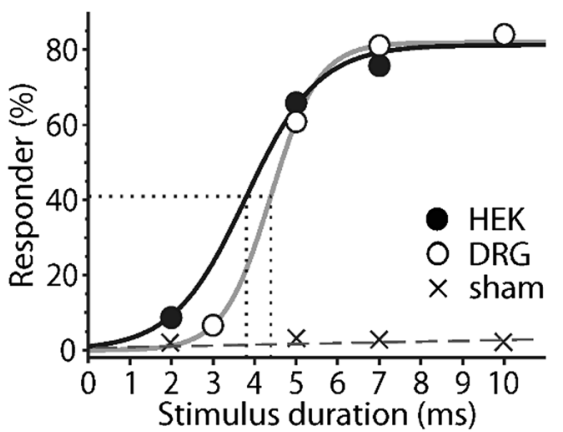

Fig. 5 Diode laser heat sensitivity is associated with capsaicin sensitivity in DRG neurons and TRPV1 transfected HEK cells. a Response frequencies of DRG neurons and $\mathbf{b}$ TRPV1 transfected HEK cells. The vast majority of cells are either excited by both stimuli, capsaicin and laser heat (C+H+, light grey) or responsive to none ( $\mathrm{C}-\mathrm{H}-$, white). c Responder rates of capsaicin sensitive DRG neurons (open) and TRPV1 transfected HEK cells (filled symbols) increase with increasing stimulation duration ( $135 \mathrm{~mW}$ ). $T_{50}$ of responding cells (dotted lines) were similar (DRG neurons $0.56 \mathrm{~mJ}, \mathrm{n}=115$ and HEK cells $0.52 \mathrm{~mJ}, \mathrm{n}=213$ ). Control data from sham-transfected HEK cells (only GFP transfected, $n=722$; crosses) show hardly any responses (overall $3.4 \%$ responders)

These data suggest that transient opening of TRPV1 by heat pulses is nearly as efficient as TRPV1 activation for $60 \mathrm{~s}$ by a saturating concentration of capsaicin.

\section{Strength duration curves for heat thresholds of DRG neurons and TRPV1 transfected HEK cells}

Capsaicin-sensitive DRG neurons (open symbols, Fig. 7), displayed almost identical $\mathrm{T}_{50}$ values for laser heat stimulation as TRPV1-expressing HEKs (filled symbols, Fig. 7). Threshold values in both cell types concerning laser power and stimulus duration were fit by a hyperbola $\left(\mathrm{R}^{2}=0.99\right.$, Fig. 7a) and displayed a rheobase of $23.7 \mathrm{~mW}$ indicating the minimum laser power for the induction of a laser heat response, and a chronaxia of $24 \mathrm{~ms}$. In both cell types, the threshold energy rose with increasing stimulus durations (Fig. 7b), suggesting lateral diffusion of heat energy due to the small stimulus spot size as a confounding factor. These data suggest that for such short stimuli, over the whole range tested, TRPV1 is the defining receptor for thermal activation thresholds in both cell types.

\section{Tachyphylaxis in laser heat induced calcium transients in HEK and DRG neurons and in human heat pain}

When stimulated repetitively ( $5 \mathrm{~ms}, 135 \mathrm{~mW}$ ) laser heat induced calcium transients were reduced from stimulus to stimulus in both cell types (TRPV1-expressing HEKs: second stimulus $46.3 \pm 2.1 \%$ of first, third $37.0 \pm 2.4 \%$ of first, $\mathrm{n}=817$; DRG neurons: $41.4 \pm 10.0 \%$ and $33.2 \pm 8.07 \%, \mathrm{n}=12$; Fig. $8 \mathrm{a}-\mathrm{c}$ ); known as tachyphylaxis of heat-evoked neuronal signaling. Pain ratings decreased when stimulated repetitively $(100 \mathrm{~mW}, 100 \mathrm{~ms}, \mathrm{n}=10)$, too, but to a significantly lesser degree (hand: second stimulus $75.1 \%(\log -0.120 \pm 0.030)$ of first, third $62.8 \%$ $(\log -0.190 \pm 0.036)$; foot: $73.5 \%(\log -0.128 \pm 0.030)$ and $62.8 \%(\log -0.188 \pm 0.040$; Fig. $8 \mathrm{~d})$. Control experiments with 297 sham transfected HEK cells (only GFP, but no TRPV1) showed no responses to repetitive heat $(135 \mathrm{~mW}, 5 \mathrm{~ms})$ nor to capsaicin $(10 \mu \mathrm{M})$; assay sensitivity was verified by responsiveness to ionomycin $(10 \mu \mathrm{M})$.

\section{Laser heat induced calcium transients are inhibited by the TRPV1 antagonist capsazepine (CPZ)}

The selective TRPV1 antagonist CPZ (10 $\mu \mathrm{M}$ for $30 \mathrm{~s})$ completely blocked calcium influx evoked by laser stimulation in half of all TRPV1 transfected HEK cells (562/1109). Remaining laser responses were significantly smaller than those after vehicle application, as CPZ reduced TRPV1 mediated laser $\mathrm{Ca}^{2+}$ transient amplitudes by $48.6 \%$ (response to second impulse $23.7 \%$ of first vs. $46.1 \%$ with vehicle; $\mathrm{p}<0.001$, unpaired t-test; Fig. 8 f).

\section{Discussion}

This study has shown that short diode laser heat stimuli $(\lambda=1470-1475 \mathrm{~nm})$ induce a rapid temperature rise (up to $320{ }^{\circ} \mathrm{C} \mathrm{s}^{-1}$ ) peaking at around $280 \mu \mathrm{m}$ tissue depth in human skin, followed by exponential decay with time constants of about $\tau=0.3 \mathrm{~s}$. Similar temperature transients were induced in DRG and HEK cells inside a microscope. Geometry and wavelength of our diode laser setups enable comparative studies of human heat pain and signal transduction in nociceptive neurons at high temporal and spatial resolution. Bias through differences in wavelength (affecting absorption and penetration 

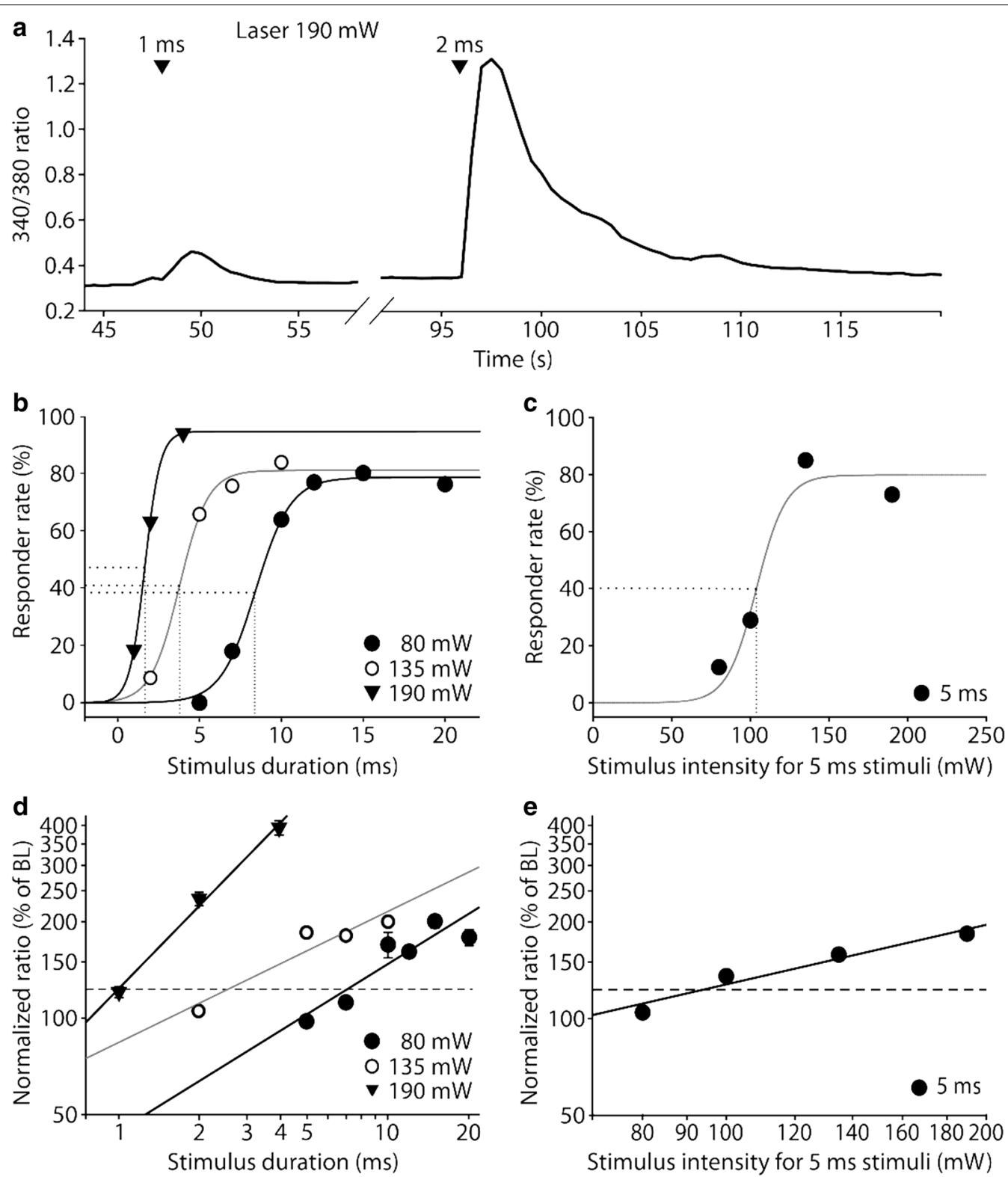

Fig. 6 Diode laser heat induced calcium transients: stimulus-response characteristics of TRPV1 transfected HEK cells. a Original trace of a single HEK cell transiently transfected with TRPV1, which showed significant responses to $190 \mathrm{~mW}$ stimuli of 1 and $2 \mathrm{~ms}$ duration. $\mathbf{b}$ Responder rates of TRPV1 transfected HEK cells as a function of stimulus duration for different laser powers (80, 135, $190 \mathrm{~mW} ; \mathrm{T}_{50}$ responder thresholds given as dotted lines; $n=142-213)$. c At fixed stimulus duration of $5 \mathrm{~ms}$ the $T_{50}$ was at $104 \mathrm{~mW}(n=666,0.52 \mathrm{~mJ})$. $\mathbf{d}$ Calcium influx linearly increased with increasing stimulus duration at fixed laser power, with Stevens' exponents between 0.40 and 0.85 (slopes). e Calcium influx linearly increased with increasing laser power at fixed duration, with a Stevens' exponent of 0.62. Dashed lines indicate upper limit of non-specific heat-induced fluorescence artefacts [18]

depth) or diameter (affecting passive cooling) was eliminated. Thus, intensity coding and tachyphylaxis can be studied across systems with nearly identical stimuli.

Laser heat pulses were painful for pulse durations above $6 \mathrm{~ms}$ (about $37.4{ }^{\circ} \mathrm{C}$ ) with mean threshold energy of $2.6 \mathrm{~mJ}\left(52.1{ }^{\circ} \mathrm{C}\right)$ on hands and $4.3 \mathrm{~mJ}\left(55.0^{\circ} \mathrm{C}\right)$ on feet. Desensitizing TRPV1-expressing skin nerve fibers with capsaicin abolished laser heat pain. TRPV1expressing HEK cells responded to laser heat pulse durations above $1 \mathrm{~ms}$ with a mean threshold of $0.52 \mathrm{~mJ}$ (0.56 $\mathrm{mJ}$ in DRG neurons). Strength duration-curves in neurons and HEK cells indicated a rheobase of $24 \mathrm{~mW}$, which likely indicates the extent of radial heat loss at 

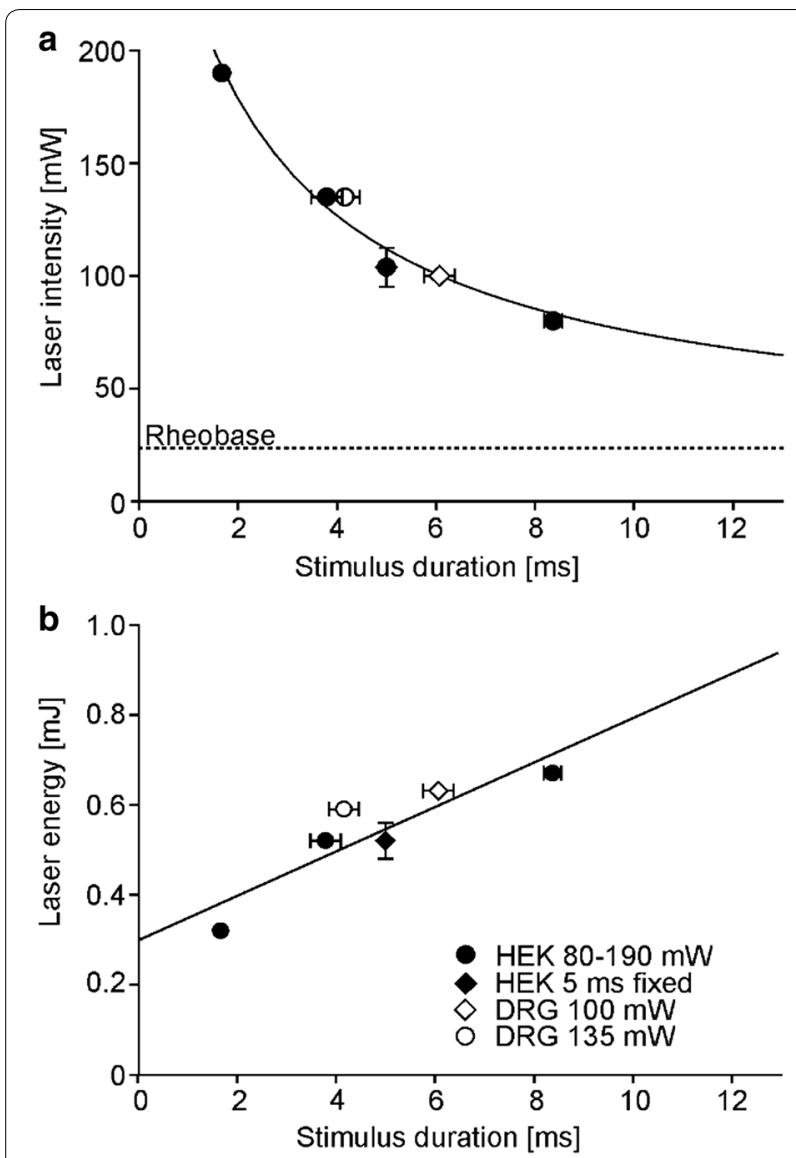

Fig. 7 Strength duration relationships-comparison of thresholds in TRPV1 transfected HEK cells and DRG neurons. a 50\% responder thresholds of DRG neurons (open) and transfected HEK cells (filled symbols) measured as laser power ( $\mathrm{mW}$ ) as a function of stimulus duration (ms). The hyperbolic fit suggests that thresholds may be expressed as a constant stimulus energy. The rheobase of the fitted function was calculated as $23.7 \mathrm{~mW}$ (dashed line). b 50\% responder thresholds calculated as applied laser energy $(\mathrm{mJ})$ plotted as a function of stimulus duration (ms). The rising linear function indicates loss of energy at the stimulation spot due to lateral thermal diffusion

equilibrium. HEK cell responses to laser heat were significantly reduced by TRPV1 antagonist CPZ.

Suprathreshold intensity coding was linear in humans across $\geq 1.5$ orders of magnitude (in double logarithmic space), while intensity coding in transfected HEK cells started saturating within less than one order of magnitude. Higher thresholds and the wider dynamic range in human psychophysics are consistent with the need for temporal and spatial summation of peripheral nociceptive input in the CNS. Upon repetitive laser stimulation, tachyphylaxis was larger in cells than in human psychophysics, suggesting partial compensation by CNS-processing.
Targeted thermal activation of nociceptive nerve endings in the skin in vivo

Free intraepidermal nerve endings are found up to the stratum lucidum, where they likely are the first line of sensors for potential or actual tissue damage. Using $\mathrm{CO}_{2}$ laser stimulation, intraepidermal nerve endings were found to be involved in peripheral encoding of noxious heat stimuli $[6,5,46,57,58]$. Functional estimates of the termination depth of nociceptive nerve endings indicate that they span a range from superficial epidermis to deep dermis (20-570 $\mu \mathrm{m}$; [54]). From psychophysical and evoked potential thresholds, a mean effective depth of $130 \mu \mathrm{m}$ has been estimated [53], which is within the subepidermal nerve fiber plexus. In human skin, both intraepidermal nerve fibers and subepidermal nerve fiber plexus express TRPV1 [42] and can be defunctionalized by high doses of topical capsaicin [3]. Deep nociceptors seem sufficient to explain heat sensitivity, since heat pain recovers more rapidly than intraepidermal nerve fiber density after topical capsaicin [50]. Our laser stimuli achieved maximum temperatures below the surface (280 $\mu \mathrm{m}$, Fig. 2), likely heating directly the TRPV1 positive fibers of the subepidermal nerve plexus [54].

\section{TRPV1-expressing HEK cells as models of nociceptive DRG neurons}

Calcium transients in HEK cells were generally larger than in DRG neurons, probably due to TRPV1 overexpression (10-20-fold above DRG, cf. [21] for TRPV3). In heat activated HEK cells, calcium flux through TRPV1 can be assumed to be the dominant source of intracellular calcium transients, whereas in DRG neurons calcium mainly flows through voltage gated calcium channels (75\% [18]) that are activated by action potentials, elicited by depolarization of the neurons via TRPV1 [20]. In our data, threshold energies did not differ significantly between DRG neurons and HEK cells, the similarity in strength-duration curves in the range of $2-10 \mathrm{~ms}$ suggests no major differences in thermal gating kinetics of native rat TRPV1 in DRG neurons and heterologously expressing HEK cells.

\section{Intensity coding in heat nociception}

Encoding noxious stimulus intensity is one of the criteria to identify a nociceptive neuron $[1,8]$. The dynamic range of intensity coding in our data was larger for psychophysical thresholds than for cellular responses, which may be explained by spatial summation of input from a population of nociceptive afferents terminating at different depths below skin surface. Spatial summation of heat pain is well known for surface stimulation of the skin using thermodes [49]. Our data suggest that spatial 

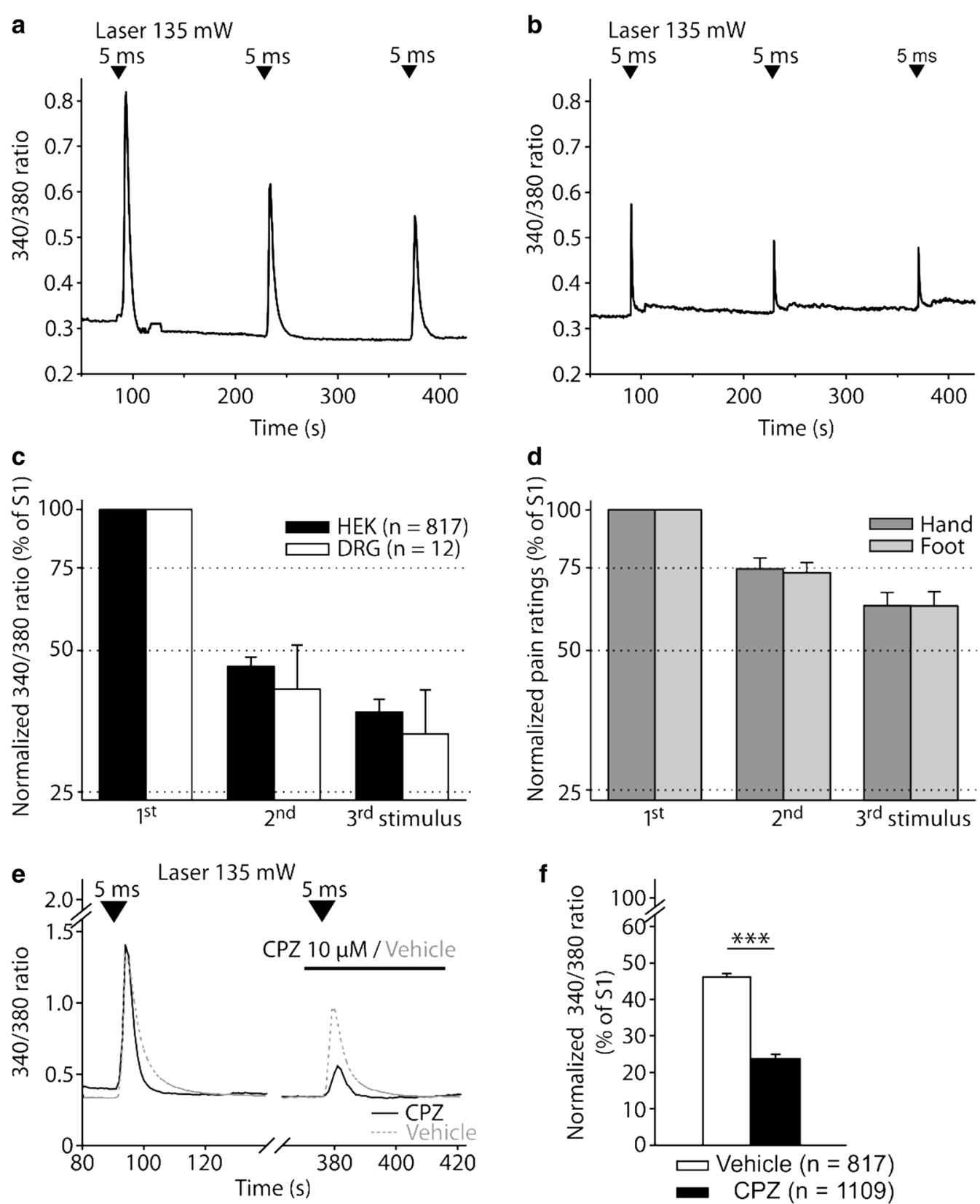

Fig. 8 Tachyphylaxis of responses to repetitive diode laser heat stimulation in vivo as well as in vitro and partial block by TRPV1 antagonist capsazepine. a Original trace of responses of a single transfected HEK cell to repetitive diode laser heat stimuli (135 mW, 5 ms). b Original trace of responses of a single DRG neuron to repetitive diode laser heat stimuli (135 mW, 5 ms). c Tachyphylaxis of diode laser heat responses in HEK cells (filled bars) and DRG neurons (open bars) challenged three times with $135 \mathrm{~mW}, 5$ ms laser stimuli (ISI $180 \mathrm{~s}$ ). Changes in fluorescence ratio normalized to first stimulus. $\mathbf{d}$ Tachyphylaxis of diode laser induced heat pain on the human hand (dark grey) and foot (light grey) when stimulating the same spot repetitively (100 mW, $200 \mathrm{~ms} ;$ ISI 180 s; n=10). e Calcium transients of representative single transfected HEK cells challenged with repeated laser stimulation ( $135 \mathrm{~mW}, 5 \mathrm{~ms}$ ) before (first stimulus) and during (second stimulus) incubation with $10 \mu \mathrm{M}$ CPZ (black trace) or with vehicle (dashed grey). Values are given in 340/380 nm fluorescence ratio. f The competitive TRPV1 antagonist capsazepine (CPZ) significantly reduced laser heat responses compared to vehicle application (by $48.6 \%$; ${ }^{* *} \mathrm{p}<0.001$, unpaired t-test)

summation also occurs between afferents terminating at different depths below surface; such populations of nociceptors will be sequentially recruited with increasing laser pulse energy. Recruitment of nociceptors with different thermal thresholds has been shown to contribute to the slowly increasing population response of type I 
AMHs (A-fiber mechano-heat nociceptor) during a prolonged burn injury [58], which in turn is thought to compensate for the pronounced adaptation of C-nociceptor response to the same stimulus [38] thus leading to a constant pain sensation.

\section{Peripheral pain memory: nociceptor fatigue and TRPV1 tachyphylaxis}

According to the dual process theory [48], repetitive stimulation always induces inhibition (habituation) and facilitation (sensitization). Human heat pain displays rapid habituation reflecting peripheral fatigue when stimulation is restricted to the same nociceptive neurons [17]. Distinct tachyphylaxis to repetitive heat applied by either diode lasers or heated superfusion is known to occur in TRPV1-transfected HEK cells [55], generator currents as well as action potential discharges of neurons $[20,52]$ and nociceptive $\mathrm{A} \delta$ - and $\mathrm{C}$-fibers in monkey and humans $[2$, 32, 45, 58]. Heterologous expression of TRPV1 inserted this type of pain memory into primarily non-excitable HEK cells. In our study, tachyphylaxis was even stronger in DRG neurons and TRPV1-expressing HEK cells than in human heat pain, probably reflecting "memory processes" distal to the first synapse of the nociceptive pathways that are partially compensated by CNS-processing. Tachyphylaxis of human heat pain, however, depends on ISI and was maximally expressed at an ISI of $10 \mathrm{~s}$ whereas reduction of heat-pain after $120 \mathrm{~s}$ (and $20 \mathrm{~min}$ ) was about 55\% (and 11\%) of maximum [51]. Therefore, our paradigm (ISIs $180 \mathrm{~s}$ to account for recovery of calcium transients) underestimated maximum tachyphylaxis in human heat pain.

Upregulation and downregulation of TRPV1 tachyphylaxis are important regulators of nociception and pain sensitivity. For example, higher heat pain sensitivity of females has been related to reduced TRPV1 tachyphylaxis mediated by estradiol [44], whereas part of the analgesic efficacy of acetylsalicylic acid is related to its enhancing effects on TRPV1 tachyphylaxis [37].

\section{TRPV1 receptor involvement in heat pain}

Our findings after defunctionalization of TRPV1 carrying nerve fibers in humans confirm their specific role in perception of phasic heat stimuli [10]. Application of high concentrated capsaicin patches $(8 \%)>10 \mathrm{~h}$ induces a complete lack of laser heat perception [24] and LEPs [50], while other sensory qualities are mostly preserved [30, 35, 36]. Similarly, pharmacological selective ablation of TRPV1 carrying nerve fibers leads to complete insensitivity to noxious heat in mice [11], rats [28] and swine [7]. However, TRPV1 knockout animals still show heat sensitivity $[9,13,62]$, suggesting additional heat transducing mechanisms in the same neurons. It was recently proposed that TRPM3 and TRPA1 contribute to heat stimulus detection, and that the lack of each single thermosensor is compensated by another in single or double knock out animals [60]. The fact that almost all heat sensitive cells in our experiments were sensitive to capsaicin, but about $10 \%$ of capsaicin sensitive cells were not sensitive to heat may be explained by near-threshold laser intensity but far suprathreshold capsaicin dose $(10 \mu \mathrm{M})$ used.

Our data indicate that TRPV1 carrying nerve fibers are necessary to transduce brief heat pulses in humans. TRPV1 is sufficient as the only excitable receptor in transfected HEK cells to detect brief laser heat pulses, and TRPV1 defines heat thresholds in rat DRG neurons and transfected HEK cells. Based on this, we suggest that non-TRPV1 heat transduction requires longer tonic stimuli and higher intensities, which are more likely to induce actual tissue damage. The role of TRPV1 in heat detection might thus be to indicate a threat of possible damage, while non-TRPV1 mediated heat detection is for actual damage.

\section{Limitations and technical considerations}

The diode laser was applied directly, through the microscope cover slip, onto the DRG neurons or HEK cells. Previous studies had either stimulated from above through the medium with energy loss via absorption and diffraction [19] or used glass fiber optics to direct the laser radiation to the cells under study $[27,64]$. Our system includes software-controlled aiming and allows stimulation of many different cells within one cover slip during the same experiment making a high cell throughput possible.

We used very small beam diameters enhancing radial heat loss and passive cooling. This allowed repetitive stimulation without heat accumulation but influenced the strength duration curve. Hyperbolic fit of strength duration curves in both, HEK cells and DRG neurons, suggests that laser pulse energy (power $\mathrm{x}$ duration, see Fig. 7) may be the relevant parameter for TRPV1 gating. However, unlike for large diameter $\mathrm{CO}_{2}$ laser stimulation of human skin [4] the threshold energies increased with increasing stimulus duration. Given the small heated volume, lateral diffusion is the most probable explanation [4]. Hence, when comparing studies and threshold values assessed with different types of laser stimulation the applied energy density (energy per area) and the diameter itself have to be taken into account. The Gaussian temperature profiles may have led to underestimation of heat sensitivity, because even for a conservative choice of beam radius (1/e), energy density at the perimeter is clearly lower than at the center and might thus not induce calcium influx. 


\section{Conclusions and outlook}

We directly compared cellular responses and human psychophysics for transient, non-damaging and punctate laser heat stimuli. We demonstrate that expression of TRPV1 fully conveys laser heat response properties observed in human heat pain and native sensory neurons to non-excitable HEK293 cells. The higher thresholds and wider dynamic range of intensity coding in humans suggests a spatial summation over a population of intraepidermal and subepidermal nociceptor populations. Our setup provides a useful mean to further study effects of transfection with other heat sensor candidates (TRPA1 or TRPM3) and their interaction with TRPV1.

\section{Abbreviations}

AMH: A-fiber mechano-heat nociceptor; $\mathrm{CMH}$ : C-fiber mechano-heat nociceptor; CNS: central nervous system; CPZ: capsazepine; DRG: dorsal root ganglion; HEK: human embryonic kidney (cells); ISI: interstimulus interval; NRS: numeric rating scale; $R T X$ : resiniferatoxin; $T_{50}: 50 \%$ responder threshold; TRPV1: Transient Receptor Potential Vanilloid 1.

\section{Acknowledgements}

We are grateful to our subjects for participation. We thank Handan Mörz and Ulrike Hortscht for technical support during the experiments and Kristina Maurer for the helpful discussions and input. We are grateful to Professor Yang and Guoliang Ke of Xiamen University, China, for kindly providing DNA beacon probes. We thank Professor Claudia Sommer, University of Würzburg, Germany, for providing the human skin samples stained for PGP9.5 and Ingo Koeper (present address: Flinders University, South Australia) for absorption measurements at the Max Planck Institute for Polymer Research, Mainz, Germany. Qutenza patches were kindly provided by Astellas Pharma GmbH (Munich, Germany). We are very thankful for the support of the International Research Training Group on Diabetic Microvascular Complications (DIAMICOM, IRTG 1874/2) and the Core Facility Live Cell Imaging Mannheim at the CBTM (LIMa, DFG INST 91027/9-1 FUGG).

\section{Authors' contributions}

All authors contributed to the conception and design of the study. DR performed the experiments and data analysis. DR and R-DT drafted the manuscript. All authors contributed to the interpretation of the data and revising the manuscript. All authors read and approved the final manuscript.

\section{Funding}

This study was supported by Deutsche Forschungsgemeinschaft (German Research Foundation, DFG): DIAMICOM (IRTG 1874) and SFB1 158 (subproject S01).

\section{Availability of data and materials}

The datasets used and/or analysed during the current study are available from the corresponding author on reasonable request.

\section{Ethics approval and consent to participate}

Human studies and DRG retrieval from rats were approved by the relevant authorities: animal welfare officer of the university clinic of Mannheim (internal notification 1-13/03) and the Medical Ethics Commission of the Medical Faculty of Mannheim, University of Heidelberg, Germany (AZ 2008-224N-MA; 2008-230A-MA).

\section{Consent for publication}

Human volunteers have consented for data to be used for research and publication purposes.

\section{Competing interests}

Qutenza patches were kindly provided as a gift by Astellas Pharma GmbH (Munich, Germany); these patches were used as a tool to desensitize the skin, Astellas was not involved in planning or performing this study. RDT reports grants from Bayer, DFG, EU, personal fees from Astellas, Bayer, Decision Resources, Grünenthal, GSK, Hydra, Pfizer, all outside the submitted work. This publication contains essential parts of the MD thesis of DR.

\section{Author details}

${ }^{1}$ Department of Neurophysiology, Mannheim Center for Translational Neuroscience (MCTN), Heidelberg University, Ludolf-Krehl-Straße 13-17, 68167 Mannheim, Germany. ${ }^{2}$ Department of Cardiovascular Physiology, European Center for Angioscience (ECAS), Medical Faculty Mannheim, Heidelberg University, Mannheim, Germany.

Received: 23 October 2019 Accepted: 26 December 2019 Published online: 17 January 2020

\section{References}

1. Adair ER, Stevens JC, Marks LE. Thermally induced pain, the dol scale, and the psychophysical power law. Am J Psychol. 1968;81:147-64.

2. Adriaensen $\mathrm{H}$, Gybels J, Handwerker $\mathrm{HO}$, van Hees J. Suppression of C-fibre discharges upon repeated heat stimulation may explain characteristics of concomitant pain sensations. Brain Res. 1984;302:203-11.

3. Anand P, Bley K. Topical capsaicin for pain management: therapeutic potential and mechanisms of action of the new high-concentration capsaicin 8\% patch. Br J Anaesth. 2011;107(4):490-502.

4. Biehl $\mathrm{R}$, Treede RD, Bromm B. Pain ratings of short radiant heat pulses. Amsterdam: Elsevier; 1984. p. 397-408.

6. Bromm B, Treede $\mathrm{RD} . \mathrm{CO}_{2}$ laser radiant heat pulses activate $\mathrm{C}$ nociceptors in man. Pflugers Arch. 1983;399(2):155-6.

5. Bromm B, Jahnke MT, Treede RD. Responses of human cutaneous afferents to $\mathrm{CO}_{2}$ laser stimuli causing pain. Exp Brain Res. 1984;55(1):158-66.

7. Brown JD, Saeed M, Do L, Braz J, Basbaum Al, ladarola MJ, Wilson DM, Dillon WP. CT-guided injection of a TRPV1 agonist around dorsal root ganglia decreases pain transmission in swine. Sci Transl Med. 2015:7(305):305ra145.

8. Carmon A, Dotan Y, Sarne Y. Correlation of subjective pain experience with cerebral evoked responses to noxious thermal stimulation. Exp Brain Res. 1978:33:445-53.

9. Caterina MJ, Leffler A, Malmberg AB, Martin WJ, Trafton J, PetersenZeitz KR, Koltzenburg M, Basbaum Al, Julius D. Impaired nociception and pain sensation in mice lacking the capsaicin receptor. Science. 2000;288:306-13.

10. Caterina MJ, Schumacher MA, Tominaga M, Rosen TA, Levine JD, Julius D. The capsaicin receptor: a heat-activated ion channel in the pain pathway. Nature. 1997;389(6653):816-24.

11. Cavanaugh DJ, Lee H, Lo L, Shields SD, Zylka MJ, Basbaum Al, Anderson DJ. Distinct subsets of unmyelinated primary sensory fibers mediate behavioral responses to noxious thermal and mechanical stimuli. Proc Natl Acad Sci USA. 2009;106(22):9075-80.

12. Chen ACN, Niddam DM, Arendt-Nielsen L. Contact heat evoked potentials as a valid means to study nociceptive pathways in human subjects. Neurosci Lett. 2001;316(2):79-82.

13. Davis JB, Gray J, Gunthorpe MJ, Hatcher JP, Davey PT, Overend P, Harries MH, Latcham J, Clapham C, Atkinson K, Hughes SA, Rance K, Grau E, Harper AJ, Pugh PL, Rogers DC, Bingham S, Randall A, Sheardown SA. Vanilloid receptor-1 is essential for inflammatory thermal hyperalgesia. Nature. 2000:405:183-7.

14. Devor M, Carmon A, Frostig R. Primary afferent and spinal neurons that respond to brief pulses of intense infrared laser radiation: a preliminary survey in rats. Exp Neurol. 1982;76:483-94.

15. Enna SJ, Williams M. Defining the role of pharmacology in the emerging world of translational research. Adv Pharmacol. 2009;57:1-30.

16. Fruhstorfer $\mathrm{H}$, Lindblom U, Schmidt WC. Method for quantitative estimation of thermal thresholds in patients. J Neurol Neurosurg Psychiatry. 1976;39(11):1071-5 
17. Greffrath W, Baumgartner U, Treede RD. Peripheral and central components of habituation of heat pain perception and evoked potentials in humans. Pain. 2007;132(3):301-11.

18. Greffrath W, Kirschstein T, Nawrath H, Treede R. Changes in cytosolic calcium in response to noxious heat and their relationship to vanilloid receptors in rat dorsal root ganglion neurons. Neuroscience. 2001;104(2):539-50.

19. Greffrath W, Nemenov MI, Schwarz S, Baumgartner U, Vogel H, ArendtNielsen L, Treede RD. Inward currents in primary nociceptive neurons of the rat and pain sensations in humans elicited by infrared diode laser pulses. Pain. 2002;99(1-2):145-55.

20. Greffrath W, Schwarz ST, Busselberg D, Treede RD. Heat-induced action potential discharges in nociceptive primary sensory neurons of rats. J Neurophysiol. 2009;102(1):424-36.

21. Grubisha O, Mogg AJ, Sorge JL, Ball LJ, Sanger H, Ruble CL, Folly EA, Ursu D, Broad LM. Pharmacological profiling of the TRPV3 channel in recombinant and native assays. Br J Pharmacol. 2014;171(10):2631-44.

22. Grynkiewicz G, Poenie M, Tsien RY. A new generation of $\mathrm{Ca}^{2+}$ indicators with greatly improved fluorescence properties. J Biol Chem. 1985:260:3440-50.

23. Haanpaa M, Attal N, Backonja M, Baron R, Bennett M, Bouhassira D, Cruccu G, Hansson P, Haythornthwaite JA, lannetti GD, Jensen TS, Kauppila T, Nurmikko TJ, Rice AS, Rowbotham M, Serra J, Sommer C, Smith BH, Treede RD. NeuPSIG guidelines on neuropathic pain assessment. Pain. 2011;152(1):14-27.

24. Henrich F, Magerl W, Klein T, Greffrath W, Treede RD. Capsaicin-sensitive C- and A-fibre nociceptors control long-term potentiation-like pain amplification in humans. Brain. 2015;138(Pt 9):2505-20.

25. Huang J, Zhang X, McNaughton PA. Modulation of temperature-sensitive TRP channels. Semin Cell Dev Biol. 2006;17(6):638-45.

26. Jacques SL. Role of tissue optics and pulse duration on tissue effects during high-power laser irradiation. Appl Opt. 1993;32(13):2447-54.

27. Jiang N, Cooper BY, Nemenov MI. Non-invasive diode laser activation of transient receptor potential proteins in nociceptors. In: Hamblin MR, Waynant RW, Anders J, editors. Mechanisms for low-light therapy II Proceedings of the SPIE. 2007.

28. Karai L, Brown DC, Mannes AJ, Connelly ST, Brown J, Gandal M, Wellisch OM, Neubert JK, Olah Z, Iadarola MJ. Deletion of vanilloid receptor 1 -expressing primary afferent neurons for pain control. J Clin Investig. 2004;113(9):1344-52.

29. Ke G, Wang C, Ge Y, Zheng N, Zhu Z, Yang CJ. L-DNA molecular beacon: a safe, stable, and accurate intracellular nano-thermometer for temperature sensing in living cells. J Am Chem Soc. 2012;134(46):18908-11.

30. Kennedy WR, Vanhove GF, Lu SP, Tobias J, Bley KR, Walk D, Wendelschafer-Crabb G, Simone DA, Selim MM. A randomized, controlled, open-label study of the long-term effects of NGX-4010, a high-concentration capsaicin patch, on epidermal nerve fiber density and sensory function in healthy volunteers. J Pain. 2010;11(6):579-87.

31. Kirschstein T, Greffrath W, Busselberg D, Treede RD. Inhibition of rapid heat responses in nociceptive primary sensory neurons of rats by vanilloid receptor antagonists. J Neurophysiol. 1999;82(6):2853-60.

32. LaMotte RH, Campbell JN. Comparison of responses of warm and nociceptive C-fiber afferents in monkey with human judgments of thermal pain. J Neurophysiol. 1978;41:509-28.

33. Leandri M, Saturno M, Spadavecchia L, lannetti GD, Cruccu G, Truini A. Measurement of skin temperature after infrared laser stimulation. Neurophysiol Clin Clin Neurophysiol. 2006;36(4):207-18.

34. Liu L, Simon SA. Capsaicin, acid and heat-evoked currents in rat trigeminal ganglion neurons: relationship to functional VR1 receptors. Physiol Behav. 2000;69(3):363-78.

35. Magerl W, Fuchs PN, Meyer RA, Treede RD. Roles of capsaicin-insensitive nociceptors in cutaneous pain and secondary hyperalgesia. Brain. 2001;124(Pt 9):1754-64.

36. Malmberg AB, Mizisin AP, Calcutt NA, von Stein T, Robbins WR, Bley KR. Reduced heat sensitivity and epidermal nerve fiber immunostaining following single applications of a high-concentration capsaicin patch. Pain. 2004;111(3):360-7.

37. Maurer K, Binzen U, Morz H, Bugert P, Schedel A, Treede RD, Greffrath W. Acetylsalicylic acid enhances tachyphylaxis of repetitive capsaicin responses in TRPV1-GFP expressing HEK293 cells. Neurosci Lett. 2014:563:101-6.
38. Meyer RA, Campbell JN. Myelinated nociceptive afferents account for the hyperalgesia that follows a burn to the hand. Science. 1981:213:1527-9.

39. Mitchell K, Bates BD, Keller JM, Lopez M, Scholl L, Navarro J, Madian N, Haspel G, Nemenov MI, ladarola MJ. Ablation of rat TRPV1-expressing Adelta/C-fibers with resiniferatoxin: analysis of withdrawal behaviors, recovery of function and molecular correlates. Mol Pain. 2010;6:94.

40. Miura A, Kawatani M. Effects of diode laser irradiation on sensory ganglion cells from the rat. Pain Res. 1996;11:175-83.

41. Mouraux A, Rage M, Bragard D, Plaghki L. Estimation of intraepidermal fiber density by the detection rate of nociceptive laser stimuli in normal and pathological conditions. Neurophysiol Clin. 2012;42(5):281-91.

42. Narayanaswamy $H$, Facer $P$, Misra VP, Timmers M, Byttebier G, Meert T, Anand P. A longitudinal study of sensory biomarkers of progression in patients with diabetic peripheral neuropathy using skin biopsies. J Clin Neurosci. 2012;19(11):1490-6.

43. Palmer KFWD. Optical properties of water in the near infrared. J Optic Soc Am. 1974;64:1107-10

44. Payrits M, Saghy E, Cseko K, Pohoczky K, Bolcskei K, Ernszt D, Barabas K, Szolcsanyi J, Abraham IM, Helyes Z, Szoke E. Estradiol sensitizes the transient receptor potential Vanilloid 1 receptor in pain responses. Endocrinology. 2017;158(10):3249-58.

45. Peng YB, Ringkamp M, Meyer RA, Campbell JN. Fatigue and paradoxical enhancement of heat response in C-fiber nociceptors from crossmodal excitation. J Neurosci. 2003;23(11):4766-74.

46. Plaghki L, Mouraux A. How do we selectively activate skin nociceptors with a high power infrared laser? Physiology and biophysics of laser stimulation. Neurophysiol Clin. 2003;33(6):269-77.

47. Pogue BW, Patterson MS. Review of tissue simulating phantoms for optical spectroscopy, imaging and dosimetry. J Biomed Opt. 2006;11(4):041102.

48. Prescott SA. Interactions between depression and facilitation within neural networks: updating the dual-process theory of plasticity. Learn Mem. 1998;5(6):446-66.

49. Price DD, McHaffie JG, Larson MA. Spatial summation of heat-induced pain: influence of stimulus area and spatial separation on stimuli on perceived pain sensation intensity and unpleasantness. J Neurophysiol. 1989:62:1270-9.

50. Rage M, Van Acker N, Facer $P$, Shenoy R, Knaapen MW, Timmers M, Streffer J, Anand P, Meert T, Plaghki L. The time course of $\mathrm{CO}_{2}$ laserevoked responses and of skin nerve fibre markers after topical capsaicin in human volunteers. Clin Neurophysiol. 2010;121(8):1256-66.

51. Rosenberger D, Magerl W, Schuh-Hofer S, Treede R-D, Greffrath W. Peripheral and central nervous contributions to changes in heat pain perception during repetitive laser stimulation in healthy subjects. In: Proceedings of the 17th world congress on pain. IASP Press; 2018 September 12-16.

52. Schwarz S, Greffrath W, Busselberg D, Treede RD. Inactivation and tachyphylaxis of heat-evoked inward currents in nociceptive primary sensory neurones of rats. J Physiol. 2000;528(Pt 3):539-49.

53. Spiegel J, Hansen C, Treede RD. Clinical evaluation criteria for the assessment of impaired pain sensitivity by thulium-laser evoked potentials. Clin Neurophysiol. 2000;111(4):725-35.

54. Tillman DB, Treede RD, Meyer RA, Campbell JN. Response of C fibre nociceptors in the anaesthetized monkey to heat stimuli: correlation with pain threshold in humans. J Physiol. 1995;485(Pt 3):767-74.

55. Tominaga M, Caterina MJ, Malmberg AB, Rosen TA, Gilbert H, Skinner K, Raumann BE, Basbaum Al, Julius D. The cloned capsaicin receptor integrates multiple pain-producing stimuli. Neuron. 1998;21(3):531-43.

56. Treede RD, Meyer RA, Campbell JN. Comparison of heat and mechanical receptive fields of cutaneous C-fiber nociceptors in monkey. J Neurophysiol. 1990;64(5):1502-13.

57. Treede RD, Meyer RA, Campbell JN. Myelinated mechanically insensitive afferents from monkey hairy skin: heat-response properties. J Neurophysiol. 1998;80(3):1082-93.

58. Treede RD, Meyer RA, Raja SN, Campbell JN. Evidence for two different heat transduction mechanisms in nociceptive primary afferents innervating monkey skin. J Physiol. 1995;483(Pt 3):747-58.

59. Truini A, Rossi P, Galeotti F, Romaniello A, Virtuoso M, De Lena C, Leandri M, Cruccu G. Excitability of the Adelta nociceptive pathways as 
assessed by the recovery cycle of laser evoked potentials in humans. Exp Brain Res. 2004;155(1):120-3.

60. Vandewauw I, De Clercq K, Mulier M, Held K, Pinto S, Van Ranst N, Segal A, Voet T, Vennekens R, Zimmermann K, Vriens J, Voets T. A TRP channel trio mediates acute noxious heat sensing. Nature. 2018;555(7698):662-6.

61. Wehling M. Translational medicine: science or wishful thinking? J Transl Med. 2008;6:31.

62. Woodbury CJ, Zwick M, Wang S, Lawson JJ, Caterina MJ, Koltzenburg M, Albers KM, Koerber HR, Davis BM. Nociceptors lacking TRPV1 and TRPV2 have normal heat responses. J Neurosci. 2004;24(28):6410-5.
63. Xia XL, Peng WW, lannetti GD, Hu L. Laser-evoked cortical responses in freely-moving rats reflect the activation of C-fibre afferent pathways. Neuroimage. 2016;128:209-17.

64. Yao J, Liu B, Qin F. Rapid temperature jump by infrared diode laser irradiation for patch-clamp studies. Biophys J. 2009:96(9):3611-9.

\section{Publisher's Note}

Springer Nature remains neutral with regard to jurisdictional claims in published maps and institutional affiliations.
Ready to submit your research? Choose BMC and benefit from:

- fast, convenient online submission

- thorough peer review by experienced researchers in your field

- rapid publication on acceptance

- support for research data, including large and complex data types

- gold Open Access which fosters wider collaboration and increased citations

- maximum visibility for your research: over $100 \mathrm{M}$ website views per year

At BMC, research is always in progress.

Learn more biomedcentral.com/submissions 